\title{
Aparelho auxiliar para cirurgia cardiovascular
}

Mário César Santos de ABREU*, Luís Lanat Pedreira de CERQUEIRA*, Álvaro RABELO Jr. *

RBCCV 44205-252

ABREU, M. C. S.; CERQUEIRA, L. L.P.; RABELOJr., A. - Aparelho auxiliar para cirurgia cardiovascular Rev. Bras. Cir. Cardiovasc., 9 (4): 224-225, 1994.

DESCRITORES: aparelhos auxiliares para cirurgia cardiovascular.

O nosso propósito é comunicar o uso de aparelho auxiliar nas operações cardiovasculares, aparelho este que vem sendo utilizado rotineiramente no Serviço de Cirurgia Cardiovascular do Hospital Professor Edgard Santos da Universidade Federal da Bahia (Figura 1).

O aparelho tem como finalidade facilitar as operações em que grande número de fios são utilizados, como, por exemplo, trocas valvares ou fechamento de comunicações intracavitárias.

A sistematização da operação fica muito simples e permite fácil integração dos componentes da equipe.

A idéia básica foi criar um instrumento cirúrgico que permitisse manter a disposição dos fios de forma ordenada, ter suporte que possibilitasse a fixação de diferentes tipos de próteses, facilitar a passagem de fios cirúrgicos e ter fixação para tração quando necessária, fixação esta que permite diferentes trações. Além disto, pode auxiliar nas medidas de ângulos nas plásticas valvares, facilitar a marcação das comissuras valvares durante as trocas, fixar fios como reparos anatômicos das bordas de átrio esquerdo, direito, ventricular, aorta, permitindo ajuste de diferentes tensões.

O aparelho é constituído de diferentes partes, sendo a base composta de um círculo de aço inoxidável, com $2,5 \mathrm{~cm}$ de largura, com diâmetro inter-

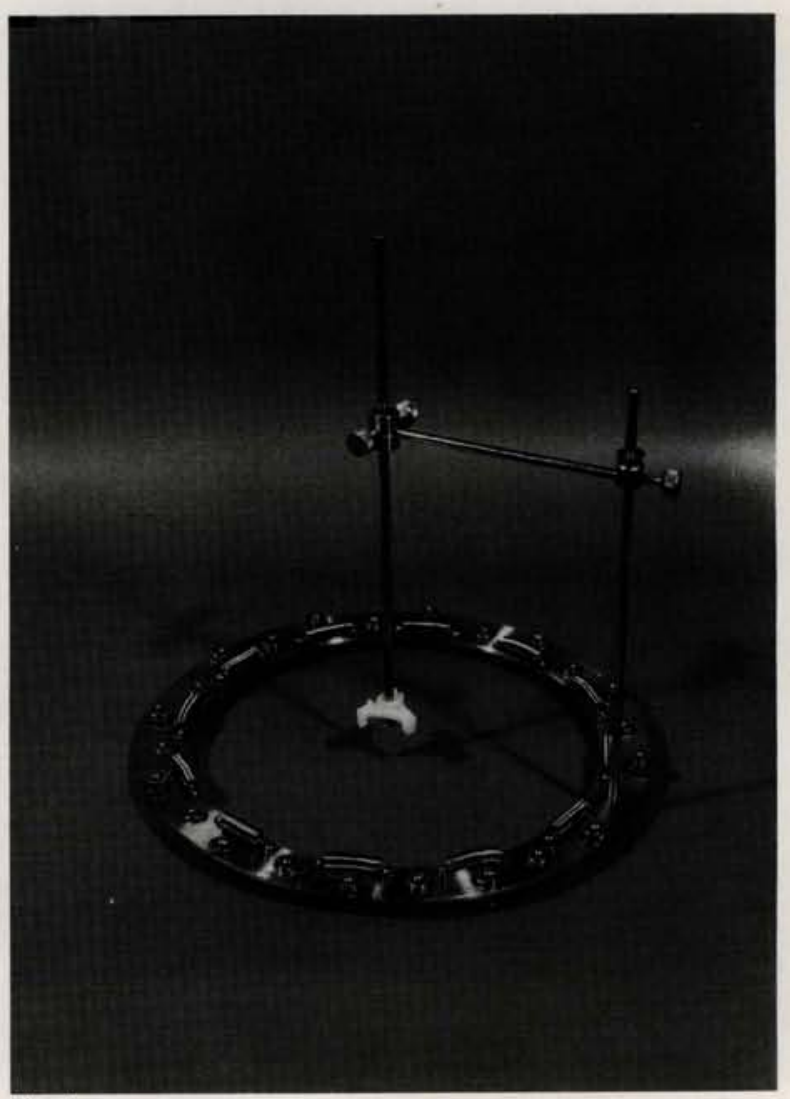

Fig. 1

Trabalho realizado no Hospital Professor Edgard Santos da Universidade Federal da Bahia. Salvador, BA, Brasil.

Recebido para publicação em dezembro de 1994.

* Do Hospital Professor Edgard Santos da Universidade Federal da Bahia.

Endereço para correspondência: Mário César de Abreu. Rua Oscar Carrascosa, n² 10, apt². 1002. Bairro Avenida. CEP 40130 Salvador, BA, Brasil. 
ABReU, M. C. S.; CERQUeIRA, L. L. P.; RABELO Jr., A. - Aparelho auxiliar para cirurgia cardiovascular Rev. Bras. Cir. Cardiovasc., 9 (4): 224-225, 1994.

no de $20 \mathrm{~cm}$, e diâmetro externo e $25 \mathrm{~cm}$. A circunferência do círculo possui marcas equidistantes de 30 graus, na parte externa. Próximo à borda foram fixadas molas, dispostas nos intervalos de 30 graus. Nos pontos intermediários às marcas de 30 graus e nas marcas de $\mathbf{3 0}$ graus, foram fixadas molas no sentido vertical, como dispositivos auxiliares, para fixação dos fios cirúrgicos, e marcação intermediária aos pontos de 30 graus. Desta forma, temos pontos marcados em todo o círculo, equidistantes de 15 graus. Em dois destes pontos, temos dois orifícios, para fixação das hastes metálicas, onde podem ser fixadas as próteses a serem implantadas, como, por exemplo, nas trocas de válvula aórtica, em que a prótese é fixada com o holder da válvula, dispensando o primeiro ajudante de manter a prótese em posição para a passagem dos fios para a fixação no anel aórtico. Este aparelho é a base para o desenvolvimento de outras adequações à cirurgia cardiovascular, como o suporte para eletrodos para eletrocardiografia intra-operatória, e mapeamento cardíaco intra-operatório (Figura 2).

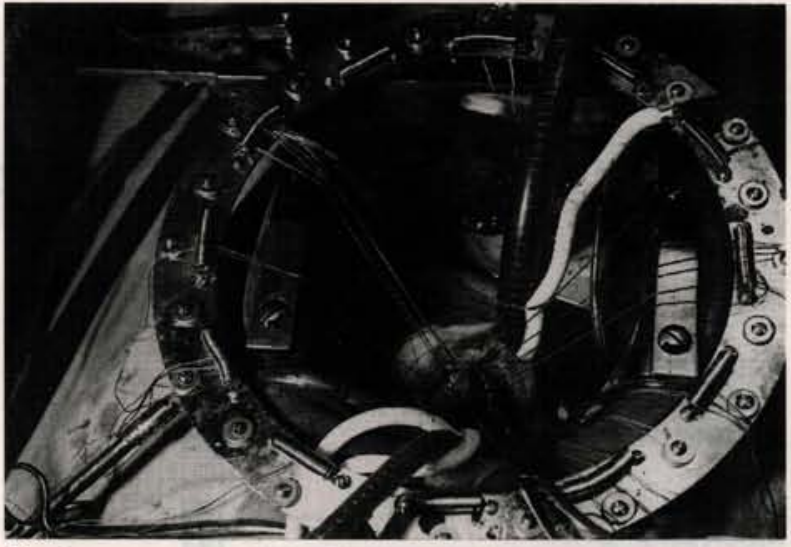

Fig. 2

Com o uso rotineiro deste aparelho em nossa equipe, notamos que ele tem facilitado as operações e que houve diminuição do tempo de clampeamento aórtico nos casos em que o mesmo foi utilizado.

ABREU, M. C.; CERQUEIRA, L. L. A.; RABELO Jr., A. - Auxiliar device for cardiovascular surgery. Rev. Bras. Cir. Cardiovasc., 9 (4): 224-225, 1994.

DESCRIPTORS: intruments, auxiliar, for cardiovascular surgery. 